\title{
Theoretical Study of the Effective Chemical Shielding Anisotropy (CSA) in Peptide Backbone, Rating the Impact of CSAs on the Cross-Correlated Relaxations in L-Alanyl-L-alanine
}

\author{
Ladislav Benda, ${ }^{*}, \dagger$ Petr Bouř, ${ }^{\dagger}$ Norbert Müller, ${ }^{*, \hbar}$ and Vladimír Sychrovský, ${ }^{*}, \dagger$ \\ Institute of Organic Chemistry and Biochemistry v.v.i., Academy of Sciences of the Czech Republic, \\ Flemingovo nám. 2, 16610 Praha 6, Czech Republic, and Institute of Organic Chemistry, Johannes Kepler \\ University, Altenbergerstrasse 69, 4040 Linz, Austria
}

Received: December 1, 2008; Revised Manuscript Received: February 3, 2009

\begin{abstract}
The dependence of the effective chemical shielding anisotropy (effective CSA, $\Delta \sigma^{\text {eff }}$ ) on the $\varphi$ and $\psi$ peptide backbone torsion angles was calculated in the L-alanyl-L-alanine (LALA) peptide using the DFT method. The effects of backbone conformation, molecular charge including the cation, zwitterion, and anion forms of the LALA peptide, and the scaling taking into account the length of the dipolar vector were calculated for the effective CSAs in order to assess their structural behaviors and to predict their magnitudes which can be probed for the $\beta$-sheet and $\alpha$-helix backbone conformations via measurement of the cross-correlated relaxation rates (CCR rates). Twenty different CSA-DD cross-correlation mechanisms involving the amide nitrogen and carbonyl carbon chemical shielding tensors and the $\mathrm{C}_{\alpha} \mathrm{H}_{\alpha}$ ( $\alpha$-carbon group), $\mathrm{NH}_{\mathrm{N}}$ (amide group), $\mathrm{C}_{\alpha} \mathrm{H}_{\mathrm{N}}$, $\mathrm{NH}_{\alpha}, \mathrm{C}^{\prime} \mathrm{H}_{\alpha}$, and $\mathrm{C}^{\prime} \mathrm{H}_{\mathrm{N}}(\alpha=\alpha 1, \alpha 2)$ dipolar vectors were investigated. The $\mathrm{X}-\mathrm{C}_{\alpha} \mathrm{H}_{\alpha}\left(\mathrm{X}=\mathrm{N}, \mathrm{C}^{\prime} ; \alpha=\alpha 1\right.$, $\alpha 2)$ cross-correlations, which had already been studied experimentally, exhibited overall best performance of the calculated effective CSAs in the LALA molecule; they spanned the largest range of values upon variation of the $\psi$ and $\varphi$ torsions and depended dominantly on only one of the two backbone torsion angles. The $\mathrm{X}-\mathrm{NH}_{\mathrm{N}}\left(\mathrm{X}=\mathrm{N}, \mathrm{C}^{\prime}\right)$ cross-correlations, which had been also probed experimentally, depended on both backbone torsions, which makes their structural assignment more difficult. The $\mathrm{N}-\mathrm{NH}_{\alpha 2}$ and $\mathrm{N}-\mathrm{C}^{\prime} \mathrm{H}_{\alpha 1}$ crosscorrelations were found to be promising for the determination of various backbone conformations due to the large calculated range of the scaled effective CSA values and due to their predominant dependence on the $\psi$ and $\varphi$ torsions, respectively. The 20 calculated dependencies of effective CSAs on the two backbone torsion angles can facilitate the structural interpretation of CCR rates.
\end{abstract}

\section{Introduction}

During the past decades, high-resolution nuclear magnetic resonance (NMR) spectroscopy has become an indispensable tool in structural studies of molecules. ${ }^{1,2}$ Applications of NMR spectroscopy for obtaining valuable structural information for biologically important molecules such as proteins and nucleic acids have grown to an unprecedented extent. ${ }^{3-7}$

Despite the marvelous progress in experimental technique, the NMR-resolved molecular structures may suffer from natural restrictions. Typically, the ${ }^{1} \mathrm{H}-{ }^{1} \mathrm{H}$ proton-proton distances probed with NOE (nuclear Overhauser effect) are not sufficient for an unambiguous determination of molecular structure. The NMR chemical shifts and scalar coupling constants can be assigned only to geometric parameters that are confined in the vicinity of the probed nuclei such as bond length or bond/torsion angle, ${ }^{3}$ contrary to the long-range structural restraints by residual dipolar couplings ${ }^{8}$ or cross-correlated relaxation rates (CCR rates). ${ }^{9}$ High resolution of the NMR-determined structures thus still remains challenging and requires methods combining various NMR parameters assigned to specific structural descriptors. New reliable geometry restraints are therefore needed in NMR studies of global structural features, such as the protein tertiary structure.

\footnotetext{
* Corresponding author.

Academy of Sciences of the Czech Republic.

Johannes Kepler University.
}

The CCR is a specific NMR phenomenon known for a long time that was relatively recently exploited in dynamic studies of biomolecules ${ }^{10-17}$ and for obtaining geometry restraints in proteins ${ }^{9,18-25}$ and in nucleic acids. ${ }^{26-33}$ The cross-correlation between chemical shielding anisotropy and dipole-dipole interaction (CSA-DD) was also used for the determination of the NMR chemical shielding tensor ( $\sigma$-tensor) principal components and their relative orientation with respect to the molecular frame even in the liquid state ${ }^{34-37}$ The applicability of the CCRs exceeds the limited range of biomolecular studies. ${ }^{38,39}$

Measurement of the CSA-DD cross-correlated relaxation rates probes both the dynamics (specific fluctuations of molecular motions) and the $\sigma$-tensor (see Theory). While reliable prediction of the CCR dynamic component might be a challenging task, ${ }^{40,41}$ the structural dependence of the $\sigma$-tensor and its orientation with respect to the dipolar vector can be obtained with many calculation methods. The theoretical modeling of NMR spectroscopy parameters using modern quantum-chemistry methods has become a practical tool that complements NMR experiments. ${ }^{42}$ The theoretical analysis of NMR parameters can provide fast and deep insight into their dependence on molecular structure including the impact of specific solvent effects and molecular motion. ${ }^{42}$ To the best of our knowledge, only a limited number of theoretical studies dealing with the ab initio modeling of NMR parameters appertained to the CCR phenomenon is currently available. ${ }^{43-45}$ The goal of this theoretical study was 
to shed light on the protocols used for the structural interpretation of relevant CSA-DD cross-correlations which can be used in probing the structure of peptide backbone. Some of the CSA-DD cross-correlation mechanisms investigated in this work were also probed in recent NMR studies. ${ }^{18-20,24,37,46}$ However, the majority of them were theoretically modeled in this work probably for the first time.

Our study was focused on the calculation of the effective CSAs for different CSA-DD cross-correlation mechanisms involving the $\sigma$-tensors of amide nitrogen $\left({ }^{15} \mathrm{~N}\right)$ and carbonyl carbon $\left({ }^{13} \mathrm{C}^{\prime}\right)$ in the L-alanyl-L-alanine (LALA) peptide. The calculated dependence of NMR properties on backbone conformation was further extended by modeling the effects of protonation and deprotonation of the LALA terminal groups occurring at different $\mathrm{pH}$ values. The three forms of the LALA molecule (cation, zwitterion, and anion) were characterized in our recent joint computational and experimental NMR work. ${ }^{47,48}$ Benchmark conformational analysis of short alanine peptides carried out with the molecular dynamics was successfully correlated with complex NMR data. ${ }^{49}$ In the future we plan to use the structural information obtained previously for the LALA molecule with both NMR and optical spectroscopies ${ }^{47,48,50}$ for calibration of measured CCR rates in peptides.

\section{Theory}

A comprehensive theoretical description of the CCR phenomenon is given by the Bloch-Wangsness-Redfield theory of relaxations, usually called the Redfield theory. ${ }^{51}$ The matrix form of relaxation equations includes the autorelaxation rates on its diagonal, whereas the off-diagonal terms describe mutual correlations between different relaxation mechanisms (i.e., the CCR rates). The CCRs typically contribute by a very small amount to the overall relaxation of a nuclear spin, and the experimental accessibility of a particular $\mathrm{CCR}$ rate can be therefore limited.

On the assumption of isotropic overall molecular motion of a molecule that can be considered rigid on the time scale of the overall molecular motion, the CSA-DD cross-correlated relaxation rate $\Gamma_{i, j k}^{\mathrm{CSA}-\mathrm{DD}}$ is described by the following equations: ${ }^{51,52}$

$$
\begin{gathered}
\Gamma_{i, j k}^{\mathrm{CSA}-\mathrm{DD}}=\frac{1}{2}\left(\frac{\mu_{0} \hbar}{4 \pi}\right) \frac{\gamma_{j} \gamma_{k}}{r_{j k}^{3}} \gamma_{i} \boldsymbol{B}_{0}\left(\Delta \sigma_{i, j k}^{\mathrm{eff}}\right) \sum_{q} \boldsymbol{J}\left(\omega_{q}\right) \\
\Delta \sigma_{i, j k}^{\mathrm{eff}}=\sum_{n=1}^{3} \sigma_{i}^{n n}\left(\frac{3 \cos ^{2} \theta_{j k}^{n n}-1}{2}\right) \\
\boldsymbol{J}\left(\omega_{q}\right)=\frac{2}{5} \frac{\tau_{\mathrm{c}}}{1+\left(\omega_{q} \tau_{\mathrm{c}}\right)^{2}}
\end{gathered}
$$

where $\boldsymbol{B}_{0}$ is the magnetic field strength, $\Delta \sigma_{i, j k}^{\text {eff }}$ is the effective CSA that correlates the principal components of the $\sigma$-tensor of nucleus $i$ with the nuclear dipolar vector interconnecting nuclei $j$ and $k, r_{j k}$ is the length of the dipolar vector, and $\theta_{j k}^{n n}$ is the angle between the $n n$-principal component of the $\sigma$-tensor and the dipolar vector. $\boldsymbol{J}\left(\omega_{q}\right)$ is the spectral density function describing the local magnetic field fluctuations at frequency $\omega_{q}$. The other symbols in eq 1 have the meaning of usual physical constants: $\gamma_{i}$ is the gyromagnetic ratio of nucleus $i, \mu_{0}$ is the vacuum permeability, and $\hbar$ is the reduced Planck constant.

The particular form of the $\boldsymbol{J}\left(\omega_{q}\right)$ function depends on the physical model of molecular motion. The spectral density function in eq 3 describes the ideal case of isotropic tumbling of a rigid spherical molecule. The rate of this tumbling is characterized by the autocorrelation time $\tau_{\mathrm{c}}$ which can be either determined experimentally by fitting the NMR data $\left(T_{1}, T_{2}\right.$, and heteronuclear NOE) or modeled theoretically with the methods of molecular dynamics. ${ }^{44}$

The $\Delta \sigma^{\text {eff }}$ essentially modulates the CCR rates (eq 1 ) via its angular dependence, projecting the principal components of the $\sigma$-tensor onto the dipolar vector of a particular CSA-DD mechanism. ${ }^{43-45}$ The spectral density function $\boldsymbol{J}\left(\omega_{q}\right)$ and the magnetic field strength $\boldsymbol{B}_{0}$ can in that regard be considered as constants. The CSA-DD cross-correlation therefore probes the site-specific mutual orientation of the $\sigma$-tensor and the dipolar vector. This theoretical study models both effects that contribute to modulation of the effective CSAs: the dependence of the $\sigma$-tensor on molecular geometry that is implicitly considered in eq 2 , and the projections of the $\sigma$-tensor principal components onto the dipolar vector. Although the latter effect is usually dominant, the former effect can be also significant, and models going beyond the so-called rigid tensor approximation are therefore more reliable. ${ }^{45}$

The experimental detection of the CSA-DD cross-correlations (generally involving three different nuclei $\mathrm{A}, \mathrm{B}, \mathrm{C}$ ) requires the development of two-spin coherences in the first step followed by measurement of differential relaxation between the doubleand zero-quantum coherences. ${ }^{46}$ The CCR rates usually cannot be accessed directly since only the $\Gamma(A-B C)+\Gamma(B-A C)$, $\Gamma(\mathrm{B}-\mathrm{AC})+\Gamma(\mathrm{C}-\mathrm{AB})$, and $\Gamma(\mathrm{C}-\mathrm{AB})+\Gamma(\mathrm{A}-\mathrm{BC})$ terms are observable. Therefore, in the most general case three independent NMR experiments have to be performed from which the three linked CCR rates can be extracted. However, if one of the CCR rates is much smaller than the other (e.g., due to a much smaller CSA value), it can be neglected and only one NMR experiment is then sufficient for the actual CCR rate determination. Further, in some cases the CCR rates can be obtained even from one-dimensional (1D) NMR spectra (for example, when only two different nuclei are involved as in the case of the $\mathrm{N}-\mathrm{NH}_{\mathrm{N}}$ cross-correlation). ${ }^{37}$

We used the usual definition of the chemical shielding anisotropy (CSA, $\Delta \sigma)$ :

$$
\Delta \sigma=\sigma^{33}-\left(\frac{\sigma^{11}+\sigma^{22}}{2}\right)
$$

where $\sigma^{n n}$ are the $\sigma$-tensor principal values defined such that $\sigma^{33}>\sigma^{22}>\sigma^{11}$.

\section{Methods}

The LALA molecule consists of two L-alanine residues. Whenever unequivocal clarity was required, we used the indexes "1" and "2" (Figure 1) to distinguish between the N-terminal and the $\mathrm{C}$-terminal residues of the LALA peptide, respectively. However, in the text we often omit the indexes, as in the case of the $\psi$ and $\varphi$ backbone torsions.

The backbone conformation of the LALA is determined by the $\psi_{1}, \omega_{1}$, and $\varphi_{2}$ torsion angles (Figure 1). The values of the $\omega$ torsion angle are close to $180^{\circ}$ in the majority of peptides due to the partial $\pi$-character of the peptide bond. The only geometry parameters describing the LALA backbone are thus the $\psi$ and $\varphi$ torsion angles.

For the anionic $\left(\mathrm{NH}_{2}\right.$ and $\mathrm{COO}^{-}$termini) and the cationic $\left(\mathrm{NH}_{3}{ }^{+}\right.$and $\mathrm{COOH}$ termini) forms of the LALA peptide both the $\psi$ and the $\varphi$ torsion angles were varied with steps of $30^{\circ}$, 

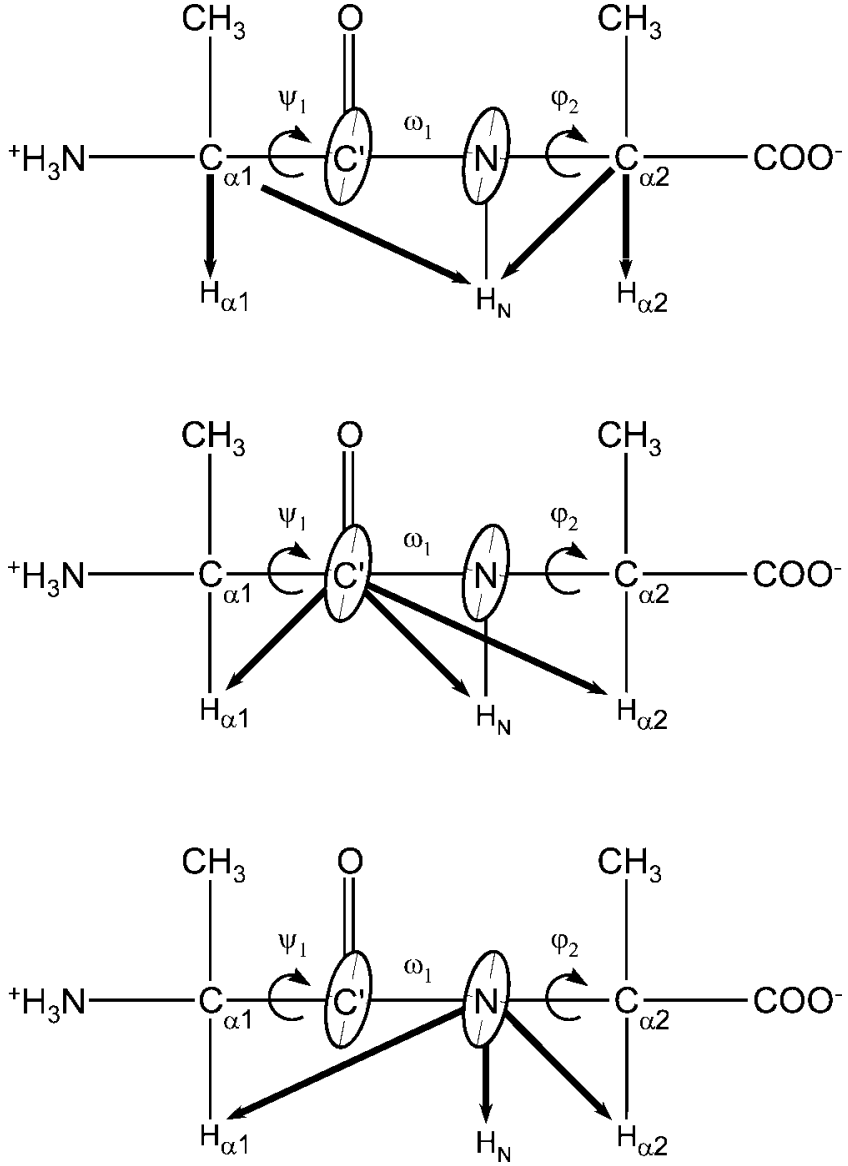

Figure 1. Schematic representation of the LALA molecule in its zwitterionic form with the indicated CSA-DD cross-correlated relaxation mechanisms between the anisotropy of $\sigma$-tensor (ellipses) and nuclear dipole-dipole vector (thick arrows).

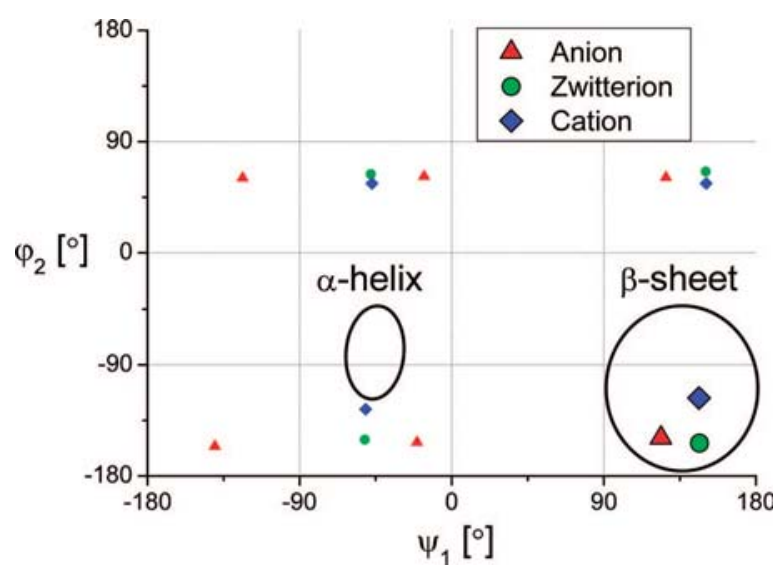

Figure 2. Localization of global (larger symbols) and local energy minima calculated for the three forms of the LALA molecule with respect to $\alpha$-helix and $\beta$-sheet regions. ${ }^{48}$

and for each of the resulting $12 \times 12=144$ geometries all the remaining coordinates were fully relaxed by energy minimization. The calculations for the zwitterion $\left(\mathrm{NH}_{3}^{+}\right.$and $\mathrm{COO}^{-}$ terminus) were performed with a larger step of $60^{\circ} .47,48$

The calculations were carried out using the density functional theory (DFT) method. The geometries and the NMR chemical shielding tensors were obtained at the BPW91 $1^{53,54} / 6-311++\mathrm{G}(\mathrm{d}, \mathrm{p})^{55}$ and the GIAO B3LYP ${ }^{56,57} / \mathrm{IGLO}^{-I^{58}}$ level of theory, respectively. The PCM dielectric model of water solvent was used consistently in both geometry optimization and NMR calculations. The Gaussian 03 program package ${ }^{59}$ was used in all quantum- chemistry calculations. The numerical evaluation of eq 2 was carried out with the Matlab program package.

\section{Results and Discussion}

The $\varphi$ and $\psi$ backbone torsion angles are essential geometry parameters for describing peptide conformation. Once their values are determined in each residue along the peptide backbone, the global structural characteristics of proteins, in particular their fold, can be explicitly studied. From this point of view, the assignment of CCR rates to backbone torsion angles represents a rather versatile restraint, since in principle a plethora of CSA-DD cross-correlated relaxation rates involving different nuclei can be measured in oligopeptides and proteins.

The experimental accessibility of all CCR rates cannot be automatically taken for granted only on the basis of the calculated effective CSAs. For example, the $r_{j k}{ }^{-3}$ factor (eq 1) scales effectively down the CCR rates with longer dipolar vectors, i.e., those with the dipolar interaction between atoms that are not directly bonded. Also, the involvement of lowgamma nuclei reduces the magnitude of cross-correlation effects. Current experimental detection of the CCR rates in peptides was therefore carried out for the dipolar vectors corresponding to covalently bonded atoms (see the $r_{\mathrm{DD}}$ column and references in Table 2) and for the high-gamma nuclei preferentially. It should be also mentioned that from the experimental point of view the magnetization transfers necessary for detection of the CCR rates with the atoms appearing in the CSA-DD mechanism separated by more bonds can be rather inconvenient and inefficient. Further, the spectral density function (eq 3 ) reflects the specificity of molecular motions with respect to a given CCR mechanism and its actual form together with the approximations usually made can significantly alter the interpretation of measured CCR rates.

We therefore found it useful to model the effective CSAs for a certain class of the CSA-DD cross-correlations which actually complemented the CCR rates that were measured in recent experimental studies (as referenced in Table 2). The crosscorrelations studied in this work involved the amide nitrogen and carbonyl carbon CSAs and the $\mathrm{C}_{\alpha 1} \mathrm{H}_{\alpha 1}, \mathrm{C}_{\alpha 2} \mathrm{H}_{\alpha 2}, \mathrm{C}_{\alpha 1} \mathrm{H}_{\mathrm{N}}$, $\mathrm{C}_{\alpha 2} \mathrm{H}_{\mathrm{N}}, \mathrm{NH}_{\mathrm{N}}, \mathrm{NH}_{\alpha 1}, \mathrm{NH}_{\alpha 2}, \mathrm{C}^{\prime} \mathrm{H}_{\mathrm{N}}, \mathrm{C}^{\prime} \mathrm{H}_{\alpha 1}$, and $\mathrm{C}^{\prime} \mathrm{H}_{\alpha 2}$ dipolar vectors (Figure 1). The dipolar vectors systematically included the $\mathrm{H}_{\alpha}$ and $\mathrm{H}_{\mathrm{N}}$ hydrogen atoms on one side and the backbone $\mathrm{C}_{\alpha}$ carbon, carbonyl carbon, and amide nitrogen on the other side. These dipolar vectors possess characteristic orientations with respect to the peptide backbone (Figure 1), and their lengths range from 1.0 to $3.0 \AA$. The calculated dependencies of the $\Delta \sigma^{\text {eff }}$ on the $\psi$ and $\varphi$ torsion angles for all three forms of the LALA peptide (cation, zwitterion, and anion) can be found in the Supporting Information.

Many aspects concerning the effective CSAs, and consequently also the CCR rates, could be theoretically modeled and analyzed. For practical applications to structural studies, a smooth dependence of the $\Delta \sigma^{\text {eff }}$ on the assigned geometry parameter(s) would be preferential. Even higher preference could be given to the cross-correlations with notable $1 \mathrm{D}$ character of the corresponding $\Delta \sigma^{\text {eff }}$, i.e. to those depending dominantly on only one geometry parameter. Strong differentiation between typical backbone conformation archetypes, such as $\alpha$-helix and $\beta$-sheet, would be another obvious advantage.

We analyzed the calculated $\Delta \sigma^{\text {eff }}$ values with such complex criteria in order to determine whether (i) the $\alpha$-helix and the $\beta$-sheet conformers of the LALA peptide could be distinguished due to sizable differences in the $\Delta \sigma^{\text {eff }}$ values (Tables 1 and 2 ) and (ii) the overall character of the $\Delta \sigma^{\text {eff }}(\psi, \varphi)$ surfaces was 

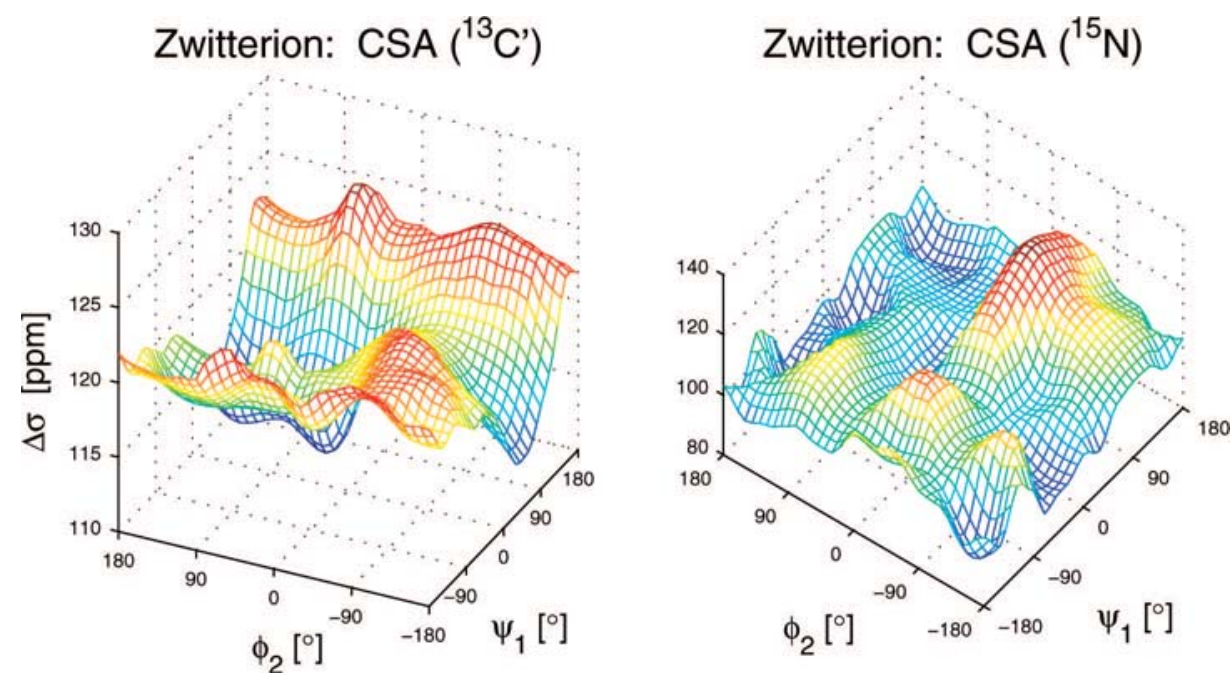

Figure 3. Dependence of the chemical shielding anisotropies $\Delta \sigma_{\mathrm{N}}$ and $\Delta \sigma_{\mathrm{C}^{\prime}}$ on the $\psi_{1}$ and $\varphi_{2}$ backbone torsion angles calculated for the LALA zwitterion.

TABLE 1: Geometry ${ }^{48}$ and NMR ${ }^{a}$ Parameters Calculated for the $\beta$-Sheet and $\alpha$-Helix Backbone Conformation of the LALA Peptide

\begin{tabular}{|c|c|c|c|c|c|c|}
\hline & \multicolumn{3}{|c|}{$\beta$-sheet ${ }^{b}$} & \multicolumn{3}{|c|}{$\alpha$-helix ${ }^{c}$} \\
\hline & anion & zwitterion & cation & anion & zwitterion & cation \\
\hline$\psi[\mathrm{deg}]$ & 119 & 147 & 149 & -30 & -30 & -30 \\
\hline$\varphi[\mathrm{deg}]$ & 210 & 207 & 239 & -90 & -90 & -90 \\
\hline$\sigma_{\mathrm{N}}[\mathrm{ppm}]$ & 91.0 & 90.1 & 100.9 & 98.5 & 94.6 & 106.0 \\
\hline$\Delta \sigma_{\mathrm{N}}[\mathrm{ppm}]$ & 125.0 & 108.8 & 105.7 & 117.6 & 101.1 & 109.1 \\
\hline$\sigma_{\mathrm{C}^{\prime}}[\mathrm{ppm}]$ & -9.6 & -0.2 & -1.5 & -12.4 & -0.5 & -0.9 \\
\hline \multirow[t]{2}{*}{$\Delta \sigma_{\mathrm{C}^{\prime}}[\mathrm{ppm}]$} & 137.4 & 123.5 & 124.4 & 144.8 & 122.5 & 123.8 \\
\hline & \multicolumn{6}{|c|}{$\Delta \sigma^{\text {eff }}[\mathrm{ppm}]$} \\
\hline CSA-DD & & & & & & \\
\hline $\mathrm{C}^{\prime}-\mathrm{C}_{\alpha 1} \mathrm{H}_{\alpha 1}$ & -26.7 & 24.0 & 30.6 & -32.3 & 5.9 & 1.7 \\
\hline $\mathrm{C}^{\prime}-\mathrm{C}_{\alpha 2} \mathrm{H}_{\alpha 2}$ & 32.7 & 44.7 & 2.6 & -3.7 & 12.1 & 21.0 \\
\hline $\mathrm{C}^{\prime}-\mathrm{C}_{\alpha 1} \mathrm{H}_{\mathrm{N}}$ & -107.9 & -84.7 & -94.6 & -96.9 & -88.6 & -97.6 \\
\hline $\mathrm{C}^{\prime}-\mathrm{C}_{\alpha 2} \mathrm{H}_{\mathrm{N}}$ & -59.6 & -79.2 & -70.8 & -69.8 & -69.8 & -60.2 \\
\hline $\mathrm{C}^{\prime}-\mathrm{NH}_{\mathrm{N}}$ & -18.4 & -8.2 & -3.3 & -31.5 & 0.0 & 2.7 \\
\hline $\mathrm{C}^{\prime}-\mathrm{NH}_{\alpha 1}$ & -93.1 & -110.9 & -108.3 & -103.2 & -102.4 & -109.7 \\
\hline $\mathrm{C}^{\prime}-\mathrm{NH}_{\alpha 2}$ & -36.1 & -53.4 & -58.7 & -56.8 & -62.3 & -48.0 \\
\hline $\mathrm{C}^{\prime}-\mathrm{C}^{\prime} \mathrm{H}_{\mathrm{N}}$ & -48.6 & -13.5 & -17.7 & -51.1 & -16.5 & -23.1 \\
\hline $\mathrm{C}^{\prime}-\mathrm{C}^{\prime} \mathrm{H}_{\alpha 1}$ & -37.9 & -57.3 & -47.2 & -99.3 & -105.4 & -109.6 \\
\hline $\mathrm{C}^{\prime}-\mathrm{C}^{\prime} \mathrm{H}_{\alpha 2}$ & -91.7 & -101.4 & -118.5 & -96.6 & -118.8 & -112.6 \\
\hline $\mathrm{N}-\mathrm{C}_{\alpha 1} \mathrm{H}_{\alpha 1}$ & -84.0 & -96.5 & -79.6 & 83.4 & 62.7 & 74.4 \\
\hline $\mathrm{N}-\mathrm{C}_{\alpha 2} \mathrm{H}_{\alpha 2}$ & -87.3 & -69.1 & -124.4 & -121.7 & -137.3 & -112.2 \\
\hline $\mathrm{N}-\mathrm{C}_{\alpha 1} \mathrm{H}_{\mathrm{N}}$ & 122.9 & 101.7 & 104.1 & 92.9 & 86.9 & 96.6 \\
\hline $\mathrm{N}-\mathrm{C}_{\alpha 2} \mathrm{H}_{\mathrm{N}}$ & -118.7 & -122.3 & -129.8 & -147.2 & -136.0 & -135.2 \\
\hline $\mathrm{N}-\mathrm{NH}_{\mathrm{N}}$ & -151.7 & -154.5 & -157.1 & -181.7 & -168.7 & -154.0 \\
\hline $\mathrm{N}-\mathrm{NH}_{\alpha 1}$ & -26.7 & -8.7 & -13.7 & 96.0 & 94.7 & 103.5 \\
\hline $\mathrm{N}-\mathrm{NH}_{\alpha 2}$ & -103.4 & -91.2 & -146.1 & -154.2 & -147.0 & -137.0 \\
\hline $\mathrm{N}-\mathrm{C}^{\prime} \mathrm{H}_{\mathrm{N}}$ & -3.4 & -18.2 & -15.8 & -32.6 & -36.4 & -17.2 \\
\hline $\mathrm{N}-\mathrm{C}^{\prime} \mathrm{H}_{\alpha 1}$ & -158.5 & -136.7 & -138.7 & 60.1 & 72.0 & 77.5 \\
\hline $\mathrm{N}-\mathrm{C}^{\prime} \mathrm{H}_{\alpha 2}$ & 34.5 & 33.0 & -8.1 & -9.8 & -3.6 & 1.6 \\
\hline
\end{tabular}

${ }^{a}$ The isotropic NMR shielding $\sigma,{ }^{48}$ the chemical shielding anisotropy $\Delta \sigma$, and the effective chemical shielding anisotropy $\Delta \sigma^{\text {eff }}$ for the CSA-DD cross-correlations. ${ }^{b}$ The geometries of global energy minima. ${ }^{c}$ Grid-point geometries close to the $\alpha$-helix region (Figure 2).

generally suitable for the structural studies in peptides (Table 2, Figures 4-6).

The composition of the solvent environment at different $\mathrm{pH}$ values clearly affects the backbone structure of the LALA peptide. ${ }^{48}$ The protonation and deprotonation occurring at the LALA termini thus represent large perturbations for NMR properties. ${ }^{48}$ The backbone geometry parameters calculated previously for the global energy minima of the three LALA forms unveiled that the zwitterion and cation forms are well localized within the $\beta$-sheet region, while the anion potential energy surface is rather flat along the $\psi$ dimension, allowing thus transitions between the $\alpha$-helix and $\beta$-sheet conformers (Figure 2) ${ }^{48}$ For the CSA-DD cross-correlated relaxation rates, we implied that those CCR mechanisms which possessed a rather stable structural dependence irrespective of the actual protonation state could be also more resistant with respect to similar structural perturbations occurring in terminal peptide residues or in polar side chains.

The optimal values of the backbone torsions corresponding to the global energy minima of the three LALA forms (the $\beta$-sheet conformation) were site-specifically affected by the protonation state (Table 1, Figure 2). The optimal values of 
TABLE 2: Summary for the Calculated Effective CSAs in the LALA Peptide

\begin{tabular}{|c|c|c|c|c|c|c|c|c|c|c|c|}
\hline $\mathrm{CSA}-\mathrm{DD}$ & $\Delta\left(\Delta \sigma^{\mathrm{eff}}\right)^{a}$ & $\Delta\left(r_{\mathrm{DD}}^{-3} \Delta \sigma^{\mathrm{eff}}\right)^{b}$ & $\Delta_{\alpha \beta}\left(\Delta \sigma^{\mathrm{eff}}\right)^{c}$ & $\Delta_{\alpha \beta}\left(r_{\mathrm{DD}}^{-3} \Delta \sigma^{\mathrm{eff}}\right)^{d}$ & $r_{\mathrm{DD}}^{e}$ & $\Delta r_{\mathrm{DD}}^{f}$ & surface $^{g}$ & pH dependence ${ }^{h}$ & $M^{i}$ & $N^{j}$ & available NMR expts \\
\hline $\mathrm{C}^{\prime}-\mathrm{C}_{\alpha 1} \mathrm{H}_{\alpha 1}$ & 200.1 & 146.1 & 18.1 & 13.5 & 1.1 & 1.4 & $\psi$ & ++ & 3 & 1 & refs 20 and $24^{l}$ \\
\hline $\mathrm{C}^{\prime}-\mathrm{C}_{\alpha 2} \mathrm{H}_{\alpha 2}$ & 151.9 & 112.8 & 32.6 & 24.4 & 1.1 & 1.0 & $\varphi$ & + & 3 & 1 & \\
\hline $\mathrm{C}^{\prime}-\mathrm{C}_{\alpha 1} \mathrm{H}_{\mathrm{N}}$ & 19.7 & 2.0 & 3.9 & -0.4 & 2.6 & 14.6 & $2 \mathrm{D}$ & $\mathrm{C}$ & 3 & 1 & \\
\hline $\mathrm{C}^{\prime}-\mathrm{C}_{\alpha 2} \mathrm{H}_{\mathrm{N}}$ & 38.7 & 4.8 & -9.4 & -0.9 & 2.1 & 6.7 & $2 \mathrm{D}$ & $\mathrm{C}$ & 3 & 1 & \\
\hline $\mathrm{C}^{\prime}-\mathrm{NH}_{\mathrm{N}}$ & 32.2 & 29.4 & -8.2 & -7.5 & 1.0 & 2.3 & $2 \mathrm{D}$ & $\mathrm{C}$ & 3 & 3 & refs 37 and $46^{k}$ \\
\hline $\mathrm{C}^{\prime}-\mathrm{NH}_{\alpha 1}$ & 47.9 & 4.5 & -8.5 & -3.4 & 2.9 & 31.1 & $\psi$ & ++ & 3 & 1 & \\
\hline $\mathrm{C}^{\prime}-\mathrm{NH}_{\alpha 2}$ & 107.6 & 12.5 & 9.0 & 1.2 & 2.1 & 3.9 & $\varphi$ & ++ & 3 & 1 & \\
\hline $\mathrm{C}^{\prime}-\mathrm{C}^{\prime} \mathrm{H}_{\alpha 1}$ & 100.7 & 10.9 & 48.1 & 5.5 & 2.1 & 5.4 & $\psi$ & ++ & 2 & 1 & \\
\hline $\mathrm{C}^{\prime}-\mathrm{C}^{\prime} \mathrm{H}_{\alpha 2}$ & 60.7 & 5.5 & 17.4 & 1.7 & 3.0 & 28.7 & $2 \mathrm{D}$ & + & 2 & 1 & \\
\hline $\mathrm{N}-\mathrm{C}_{\alpha 1} \mathrm{H}_{\alpha 1}$ & 215.6 & 160.4 & -159.2 & -118.9 & 1.1 & 1.4 & $\psi$ & 0 & 3 & 1 & ref 19 \\
\hline $\mathrm{N}-\mathrm{C}_{\alpha 2} \mathrm{H}_{\alpha 2}$ & 222.5 & 166.6 & 68.2 & 51.1 & 1.1 & 1.0 & $\varphi$ & 0 & 3 & 1 & ref 18 \\
\hline $\mathrm{N}-\mathrm{C}_{\alpha 1} \mathrm{H}_{\mathrm{N}}$ & 94.5 & 5.9 & 14.8 & 1.5 & 2.6 & 14.6 & $2 \mathrm{D}$ & + & 3 & 1 & \\
\hline $\mathrm{N}-\mathrm{C}_{\alpha 2} \mathrm{H}_{\mathrm{N}}$ & 62.3 & 5.9 & 13.8 & 1.6 & 2.1 & 6.7 & $2 \mathrm{D}(\varphi)$ & + & 3 & 1 & \\
\hline $\mathrm{N}-\mathrm{NH}_{\mathrm{N}}$ & 72.1 & 69.2 & 14.3 & 15.1 & 1.0 & 2.3 & $2 \mathrm{D}$ & 0 & 2 & 1 & refs 37 and 46 \\
\hline $\mathrm{N}-\mathrm{NH}_{\alpha 1}$ & 148.1 & 5.8 & -103.4 & -3.1 & 2.9 & 31.1 & $\psi$ & 0 & 2 & 1 & \\
\hline $\mathrm{N}-\mathrm{C}^{\prime} \mathrm{H}_{\mathrm{N}}$ & 68.8 & 8.7 & 18.2 & 2.0 & 2.1 & 6.7 & $2 \mathrm{D}(\varphi)$ & 0 & 3 & 3 & refs 37 and $46^{k}$ \\
\hline $\mathrm{N}-\mathrm{C}^{\prime} \mathrm{H}_{\alpha 1}$ & 256.1 & 26.2 & -208.7 & -20.2 & 2.1 & 5.4 & $\psi$ & 0 & 3 & 1 & \\
\hline $\mathrm{N}-\mathrm{C}^{\prime} \mathrm{H}_{\alpha 2}$ & 141.8 & 5.0 & 36.6 & 2.0 & 3.0 & 28.7 & $\varphi$ & + & 3 & 1 & \\
\hline
\end{tabular}

${ }^{a}$ The maximal calculated difference between the maximum and minimum values on the $\Delta \sigma^{\text {eff }}$ surface among the three forms of the LALA peptide; $\Delta\left(\Delta \sigma^{\text {eff }}\right)$ [ppm]. ${ }^{b}$ The maximal calculated difference between the maximum and minimum values on the $r_{\mathrm{DD}}{ }^{-3} \Delta \sigma^{\text {eff }}$ surface among the three forms of the LALA peptide; $\Delta\left(r_{\mathrm{DD}}{ }^{-3} \Delta \sigma^{\text {eff }}\right) \quad\left[\AA^{-3} \mathrm{ppm}\right] .{ }^{c}$ The difference between the $\Delta \sigma^{\text {eff }}$ values calculated for the $\beta$-sheet and the $\alpha$-helix conformation in the LALA zwitterion (Table 1$) ; \Delta_{\alpha \beta}\left(\Delta \sigma^{\text {eff }}\right)$ [ppm]. ${ }^{d}$ The difference between the $r_{\mathrm{DD}}{ }^{-3} \Delta \sigma^{\text {eff }}$ values calculated for the $\beta$-sheet and the $\alpha$-helix conformation in the LALA zwitterion (Table 1$) ; \Delta_{\alpha \beta}\left(r_{\mathrm{DD}}{ }^{-3} \Delta \sigma^{\text {eff }}\right.$ ) [Å ${ }^{-3}$ ppm]. ${ }^{e}$ The average length of the dipolar vector $[\AA] .{ }^{f}$ The maximal deviation of the dipolar vector length on the $(\psi, \varphi)$ grid relative to the average length; $\Delta r_{\mathrm{DD}}[\%]$. ${ }^{g}$ The dominant structural dependence of the $(\psi, \varphi)$ surfaces calculated for the $\Delta \sigma^{\text {eff }}$ (Supporting Information) (the surfaces significantly modulated in both dimensions are denoted "2D"). "Qualitative classification of the $\Delta \sigma^{\text {eff }}$ surfaces variation between the three charged LALA forms ("+ +" stands for "large", "+" for "small", "C" for "complex", and "0" for "negligible"). "The number of nuclei involved in the CSA-DD cross-correlation. ${ }^{j}$ The number of independent NMR experiments needed for the experimental detection of CCR rate. ${ }^{k}$ Only the linked $\Gamma\left(\mathrm{C}^{\prime}, \mathrm{NH}_{\mathrm{N}}\right)+\Gamma\left(\mathrm{N}, \mathrm{C}^{\prime} \mathrm{H}_{\mathrm{N}}\right), \Gamma\left(\mathrm{N}, \mathrm{C}^{\prime} \mathrm{H}_{\mathrm{N}}\right)+\Gamma\left(\mathrm{H}_{\mathrm{N}}, \mathrm{NC}^{\prime}\right)$, or $\Gamma\left(\mathrm{H}_{\mathrm{N}}, \mathrm{NC}^{\prime}\right)+\Gamma\left(\mathrm{C}^{\prime}, \mathrm{NH}_{\mathrm{N}}\right)$ terms can be measured. ${ }^{l} \mathrm{The}$ inseparable term $\Gamma\left(\mathrm{C}_{\alpha}, \mathrm{C}^{\prime} \mathrm{H}_{\alpha}\right)$ was considered to be negligible due to the small $\mathrm{C}_{\alpha}-\mathrm{CSA}$.

the $\psi$ torsion angle obtained for the zwitterion and cation were similar since the $\mathrm{NH}_{3}{ }^{+}$terminus remained unchanged in these two forms, while for the anion (the $\mathrm{NH}_{2}$ terminus) $\psi$ increased by $\sim 20^{\circ}$ (Table 1). Similar behavior was found for the $\varphi$ angle; the value calculated in the cation $(\mathrm{COOH})$ was larger by $\sim 30^{\circ}$ compared to both the anion and the zwitterion $\left(\mathrm{COO}^{-}\right)$. These backbone conformational changes were reflected by the values of the amide nitrogen $\left(\sigma_{\mathrm{N}}\right)$ and the carbonyl carbon $\left(\sigma_{\mathrm{C}^{\prime}}\right)$ isotropic shielding constants that had been analyzed in detail previously $^{48}$ (see also Table 1). Similar correlations could be observed for the chemical shielding anisotropies $\Delta \sigma_{\mathrm{N}}$ and $\Delta \sigma_{\mathrm{C}^{\prime}}$ (eq 4) with the exception of $\Delta \sigma_{\mathrm{N}}$ in the zwitterion, which was closer to the value calculated for the cation (Table 1). The calculated dependencies of $\Delta \sigma_{\mathrm{N}}$ and $\Delta \sigma_{\mathrm{C}^{\prime}}$ on the $\psi$ and $\varphi$ backbone torsion angles were significantly modulated in both dimensions (Figure 3).

The $\Delta \sigma^{\text {eff }}$ values calculated for the $\beta$-sheet and $\alpha$-helix conformers (Table 1 ) certainly provide an alternative approach for the identification of the respective conformers in LALA dipeptide and (due to the local character of NMR properties) probably also generally in oligopeptides and proteins. Large differences of the calculated $\Delta \sigma^{\text {eff }}$ values between $\beta$-sheet and $\alpha$-helix could be considered as a qualitative indicator for their possible distinguishing with the CCR rates (Tables 1 and 2). In order to estimate the $\Delta \sigma^{\text {eff }}$ values in the $\alpha$-helix conformation, we used one of the grid points in a vicinity of that region (Table 1 , Figure 2), while the geometries of global energy minima for all LALA forms were used as models for the $\beta$-sheet conformation. The calculated absolute $\Delta \sigma^{\text {eff }}$ differences between the $\beta$-sheet and $\alpha$-helix conformations $\left(\left|\Delta_{\alpha \beta} \Delta \sigma^{\text {eff }}\right|\right)$ in the LALA zwitterion spanned a relatively wide range: $3-48 \mathrm{ppm}$ and 14-209 ppm for the cross-correlations involving carbonyl carbon and amide nitrogen, respectively (Table 2). For the crosscorrelations that were recently probed experimentally (see the references in Table 2), the $\left|\Delta_{\alpha \beta} \Delta \sigma^{\text {eff }}\right|$ absolute differences in the LALA zwitterion were 18,8 , and 3 ppm $\left(\mathrm{C}^{\prime}-\mathrm{C}_{\alpha 1} \mathrm{H}_{\alpha 1}, \mathrm{C}^{\prime}-\mathrm{NH}_{\mathrm{N}}\right.$, $\left.\mathrm{C}^{\prime}-\mathrm{C}^{\prime} \mathrm{H}_{\mathrm{N}}\right)$ and $160,68,14$, and $18 \mathrm{ppm}\left(\mathrm{N}-\mathrm{C}_{\alpha 1} \mathrm{H}_{\alpha 1}, \mathrm{~N}-\mathrm{C}_{\alpha 2} \mathrm{H}_{\alpha 2}\right.$, $\mathrm{N}-\mathrm{NH}_{\mathrm{N}}, \mathrm{N}-\mathrm{C}^{\prime} \mathrm{H}_{\mathrm{N}}$ ).

The effective CSAs calculated for one backbone conformation in the three LALA forms reflected the structural changes due to different $\mathrm{pH}$ values in a similar way as calculated for the isotropic shieldings ${ }^{48}$ and CSAs (Table 1). The $\Delta \sigma^{\text {eff }}$ values calculated in $\beta$-sheet geometries for the $\mathrm{C}^{\prime}-\mathrm{C}_{\alpha 1} \mathrm{H}_{\alpha 1}$ (zwitterion and cation) and $\mathrm{C}^{\prime}-\mathrm{C}_{\alpha 2} \mathrm{H}_{\alpha 2}$ (anion, zwitterion) cross-correlations ranged over relatively narrow intervals $(24-31 \mathrm{ppm}$ and 33-45 ppm, respectively) compared to the $\mathrm{C}^{\prime}-\mathrm{C}_{\alpha 1} \mathrm{H}_{\alpha 1}$ effective CSA in the anion (-27 ppm) and the $\mathrm{C}^{\prime}-\mathrm{C}_{\alpha 2} \mathrm{H}_{\alpha 2}$ effective CSA in the cation $(3 \mathrm{ppm})$ (Table 1$)$.

The calculated $\Delta \sigma^{\text {eff }}(\psi, \varphi)$ surfaces are rather universal since they show overall trends which should be more or less valid in peptides unless some larger effect perturbed the local nature of this NMR parameter (for example, the proximity of an aromatic ring or an additional charge). The dependencies of the $\Delta \sigma^{\text {eff }}$ $(\psi, \varphi)$ surfaces on $\mathrm{pH}$ can also help to estimate the stability of a particular cross-correlation mechanism with regard to the fluctuating total charge of a peptide molecule (Table 2). Global characteristics of the $(\psi, \varphi)$ surfaces (Table 2), structural variation of the calculated $\Delta \sigma^{\text {eff }}$ values (Supporting Information), and the $r_{j k}{ }^{-3}$ scaling (Table 2, Figure 6B) can provide a reliable estimate for the conformational dependence of the CCR rates.

The magnitudes of CSA-DD cross-correlation effects are of course very much dependent on the angular projections of the $\sigma$-tensor principal components on the particular dipolar vector (eq 2). In this sense, the CSA and the effective CSA can be regarded 

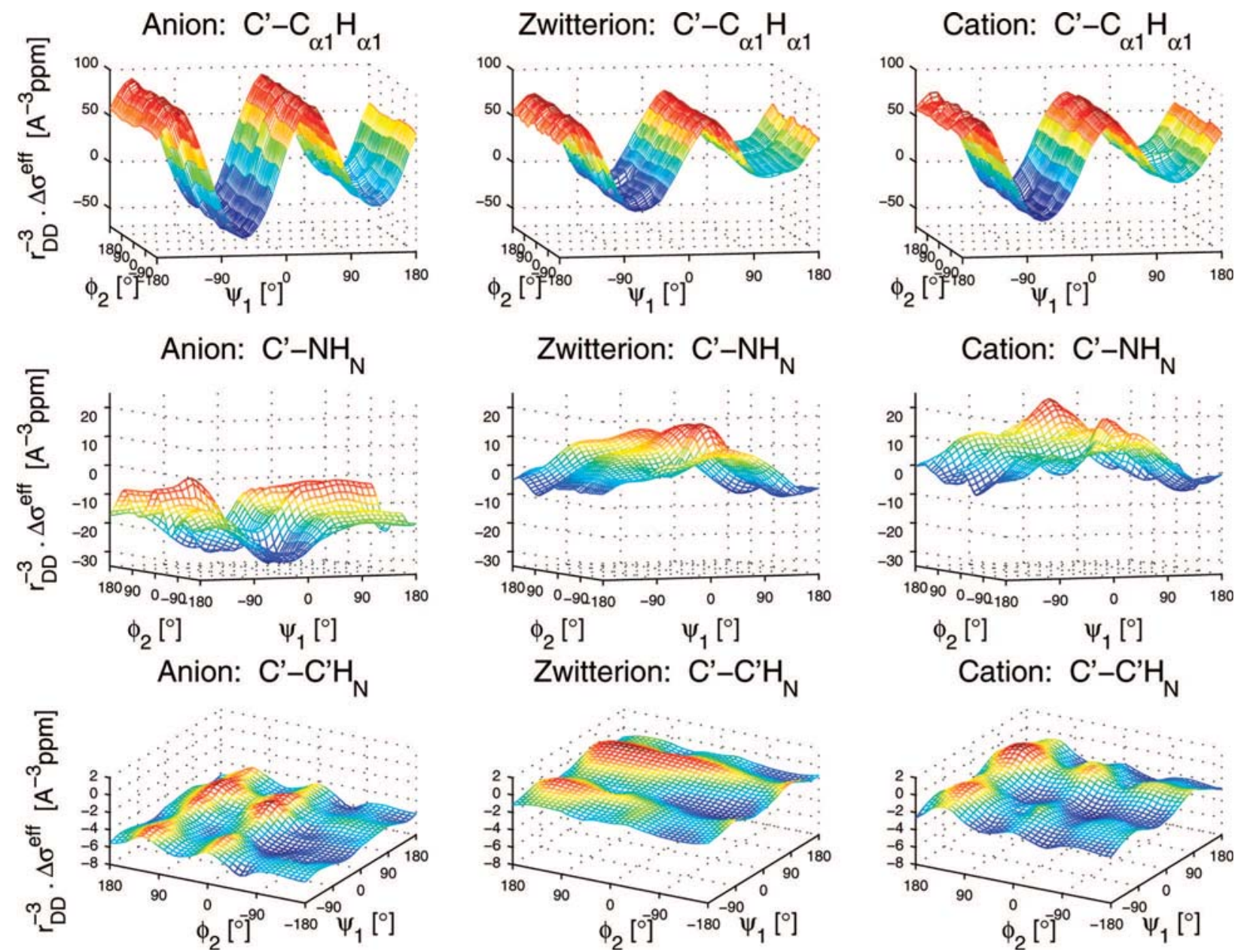

Figure 4. Dependence of selected $\Delta \sigma^{\text {eff }}$ on the $\psi_{1}$ and $\varphi_{2}$ backbone torsion angles calculated for the three forms of the LALA molecule and scaled with the length of the dipolar vector. The cross-correlation mechanisms involved the carbonyl carbon $\sigma$-tensor and the $\mathrm{C}_{\alpha 1} \mathrm{H}_{\alpha 1}, \mathrm{NH}_{\mathrm{N}}$, and $\mathrm{C}^{\prime} \mathrm{H}_{\mathrm{N}}$ dipolar vectors.

as two different linear combinations of the $\sigma$-tensor principal values, one with constant coefficients (eq 4) and the other with molecular structure dependent coefficients (eq 2). The relative importance of the angular projections in comparison to the variation of the shielding tensor itself is thus immediately seen. The range of values calculated for the $\Delta \sigma_{\mathrm{N}}$ and $\Delta \sigma_{\mathrm{C}^{\prime}}$ CSAs on the $(\psi, \varphi)$ grid (Figure 3 ) was relatively small compared to the ranges calculated for the effective anisotropies $\Delta \sigma^{\text {eff }}$ (eq 2, Figure 6A, Supporting Information), which were modulated specifically by the particular choice of the DD vector. Moreover, the calculated $(\psi, \varphi)$ surfaces of the $\Delta \sigma_{\mathrm{N}}$ and $\Delta \sigma_{\mathrm{C}^{\prime}}$ anisotropies possessing a significant " $2 \mathrm{D}$ character" (i.e., the dependence on both torsion angles, see Figure 3) could have been smoothed or even may have lost their 2D character for a suitable choice of the DD vector. Such effective CSAs are rather attractive with regard to their direct structural interpretation (see the surface classification in Table 2 and the Supporting Information). Vice versa, the choice of the $\sigma$-tensor may also have resulted in a qualitatively different performance of the respective effective CSAs for one dipolar vector (see, for example, the $\mathrm{C}^{\prime}-\mathrm{C}^{\prime} \mathrm{H}_{\alpha 2}$ and $\mathrm{N}-\mathrm{C}^{\prime} \mathrm{H}_{\alpha 2}$ effective CSAs in Table 2 and in the Supporting Information).

The experimentally rather easily accessible $\mathrm{N}-\mathrm{NH}_{\mathrm{N}}$ crosscorrelation is a particularly interesting parameter due to the amide nitrogen being the CSA center and the origin of the DD vector. The orientation of the DD vector with respect to the molecular frame remained quite similar for all backbone conformations. The $\mathrm{N}-\mathrm{NH}_{\mathrm{N}}$ effective CSA therefore depended mainly on reorientation and magnitude alteration of the nitrogen $\sigma$-tensor principal com- ponents upon variation of the backbone torsions. The calculated $(\psi, \varphi)$ surfaces of the $\mathrm{N}-\mathrm{NH}_{\mathrm{N}}$ effective CSA (Supporting Information) were thus significantly modulated in both $\psi$ and $\varphi$ dimensions (Figure 5), similarly to the chemical shielding anisotropy $\Delta \sigma_{\mathrm{N}}$ of the amide nitrogen (Figure 3). It should be however noted that in the case of hydrogen bonding both the direction and length of the $\mathrm{NH}_{\mathrm{N}}$ vector may vary considerably.

The $\Delta \Delta \sigma^{\text {eff }}$ values, i.e., the differences between maximum and minimum of the calculated $\Delta \sigma^{\text {eff }}$ on the whole $(\psi, \varphi)$ surface, were used to estimate the extent of the effective CSA modulation by the variation of the two torsion angles. For the $\mathrm{X}-\mathrm{C}_{\alpha} \mathrm{H}_{\alpha}(\mathrm{X}$ $\left.=\mathrm{N}, \mathrm{C}^{\prime} ; \alpha=\alpha 1, \alpha 2\right)$ cross-correlations, the $\Delta \Delta \sigma^{\text {eff }}$ values were large (Table 2, Figure 6A) and the $\Delta \sigma^{\text {eff }}(\psi, \varphi)$ surfaces depended predominantly on the $\varphi\left(\mathrm{X}-\mathrm{C}_{\alpha 2} \mathrm{H}_{\alpha 2}\right)$ or $\psi\left(\mathrm{X}-\mathrm{C}_{\alpha 1} \mathrm{H}_{\alpha 1}\right)$ torsion angles (Table 2, Supporting Information). These cross-correlations thus appear to be well suited for the peptide structural studies since they exhibit smooth and specific dependences on the backbone conformation, which is at the same time notably modulated (Table 2, Figures 4-6, and Supporting Information).

A somewhat lower applicability for the peptide structural studies could be expected from the rest of the cross-correlations involving the carbonyl carbon CSA. The $\left|\Delta_{\alpha \beta} \Delta \sigma^{\text {eff }}\right|$ absolute differences were mostly small (exceeding 20 ppm in only two cases; see Tables 1 and 2), and the corresponding surfaces had usually pronounced 2D character often combined with significant $\mathrm{pH}$ dependence (Table 2) or shallow modulation (Figure 6A).

The effective CSAs involving the amide nitrogen $\sigma$-tensor performed significantly better. The calculated $\Delta \Delta \sigma^{\text {eff }}$ values 

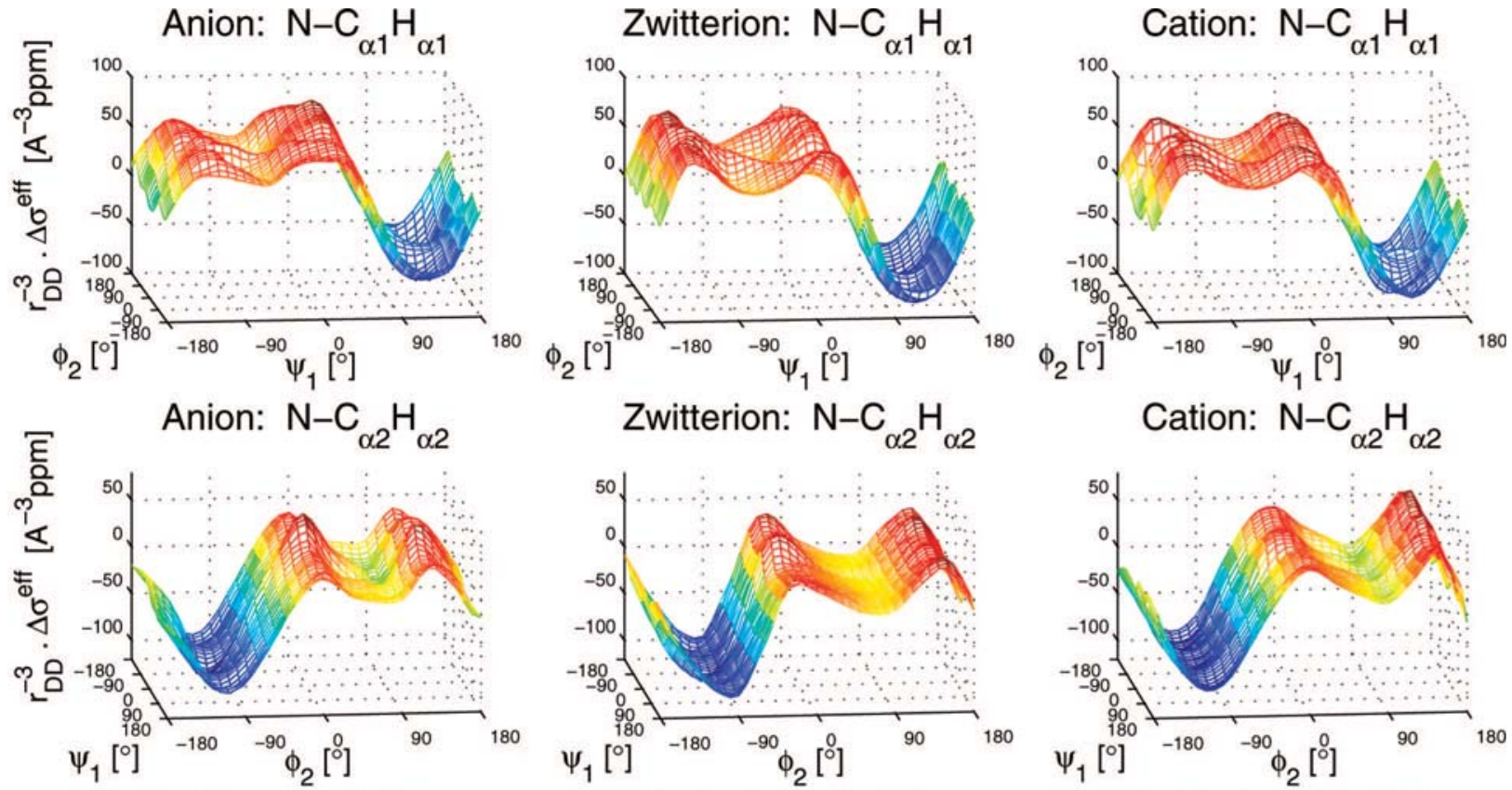

Zwitterion: $\mathrm{N}-\mathrm{C}_{\alpha 2} \mathrm{H}_{\alpha 2}$

Cation: $\mathrm{N}-\mathrm{C}_{\alpha 2} \mathrm{H}_{\alpha 2}$
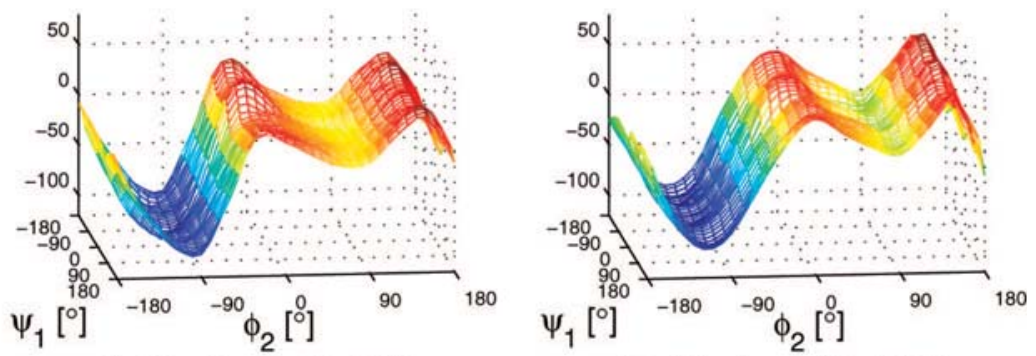

Zwitterion: $\mathrm{N}-\mathrm{NH}_{\mathrm{N}}$
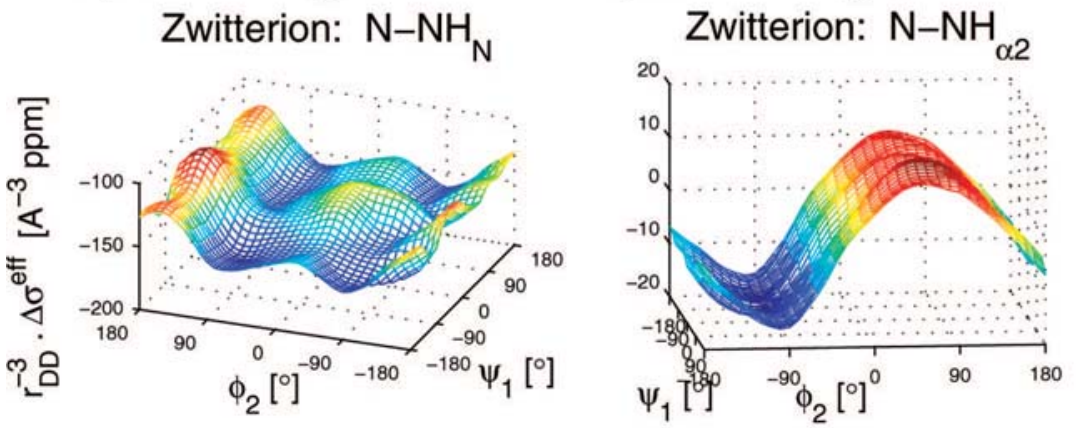

Zwitterion: $\mathrm{N}-\mathrm{C}^{\prime} \mathrm{H}_{\alpha 1}$

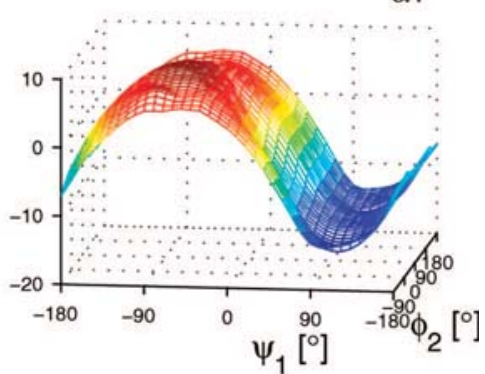

Figure 5. Dependence of selected $\Delta \sigma^{\text {eff }}$ on the $\psi_{1}$ and $\varphi_{2}$ backbone torsion angles scaled with the length of the dipolar vector. The cross-correlation mechanisms involved the amide nitrogen $\sigma$-tensor and the $\mathrm{C}_{\alpha 1} \mathrm{H}_{\alpha 1}, \mathrm{C}_{\alpha 2} \mathrm{H}_{\alpha 2}, \mathrm{NN}_{\mathrm{H}}, \mathrm{NH}_{\alpha 2}$, and $\mathrm{C}^{\prime} \mathrm{H}_{\alpha 1}$ dipolar vectors.
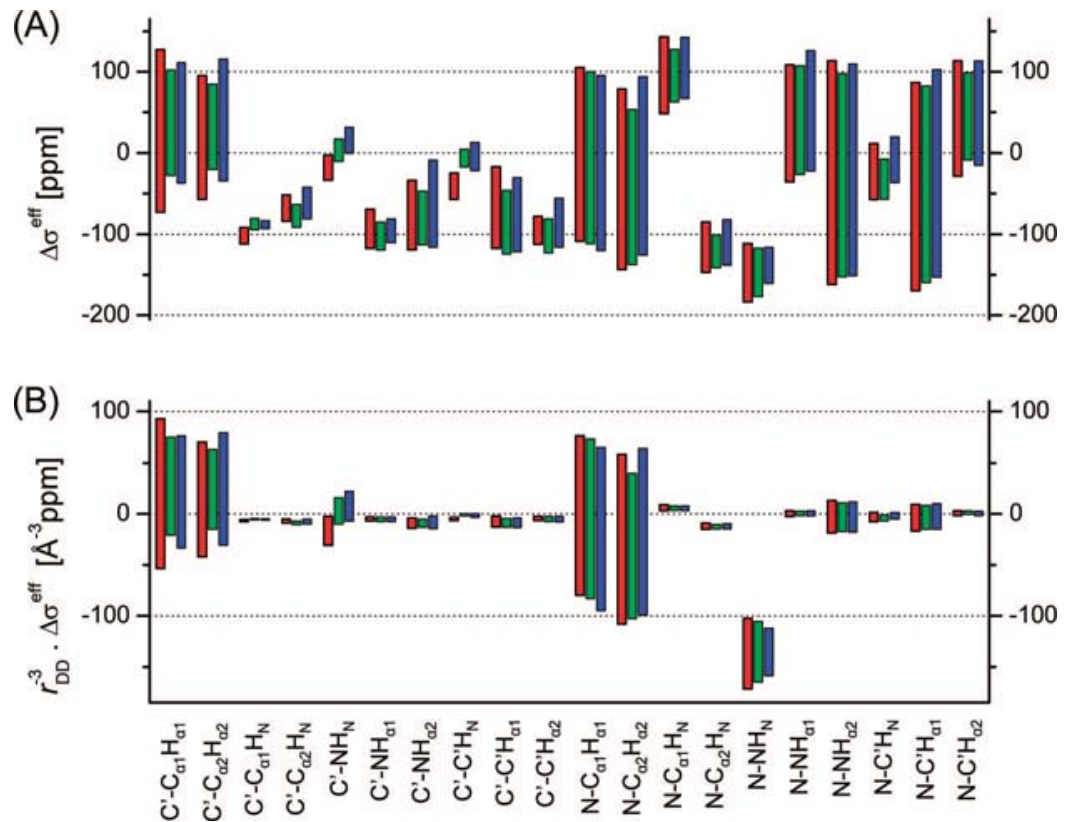

Figure 6. (A) Ranges of the effective CSA values corresponding to their maxima/minima on the $(\psi, \varphi)$ surfaces calculated in the anion (red), zwitterion (green), and cation (blue) forms of the LALA molecule. (B) Calculated ranges of $\Delta \sigma^{\text {eff }}$ scaled with the $r_{\mathrm{DD}}{ }^{-3}$ factor, where $r_{\mathrm{DD}}$ is the length of the dipolar vector.

were overall larger than those involving the carbonyl carbon CSA (Figure 6). Also the $(\psi, \varphi)$ surfaces of the nitrogen effective
CSA were more often dominated by only a single torsion, and their $\mathrm{pH}$ dependence was smaller (Table 2, Supporting Informa- 
tion). In addition to the four cross-correlations involving the amide nitrogen CSA, which were probed in recent experimental studies (references in Table 2), we found similar $\Delta \Delta \sigma^{\text {eff }}$ magnitudes for the $\mathrm{N}-\mathrm{NH}_{\alpha}$ and $\mathrm{N}-\mathrm{C}^{\prime} \mathrm{H}_{\alpha}(\alpha=\alpha 1, \alpha 2)$ effective CSAs. These cross-correlations might be also good candidates for the structural studies in peptides, since they depend mostly on a single torsion angle and their $\mathrm{pH}$ variation is negligible.

A comprehensive analysis of the calculated effective CSAs that can be used for a reliable estimate of the CCR rates must take into account their scaling with the length of the dipolar vector $\left(r_{j k}{ }^{-3}\right.$ factor in eq $1, r_{\mathrm{DD}}{ }^{-3}$ column in Table 2$)$. The scaling substantially reduced the $\Delta \sigma^{\text {eff }}$ values for the cross-correlations with longer dipolar vectors (Table 2, Figure 6B). The length of the DD vector thus can be a rather limiting factor for the experimental accessibility of the CCR rates. On the other hand, the grid point dependent lengths of the investigated DD vectors varied only up to $2.3,6.7$, and $31.1 \%$ (relative to the average value) for the DD vectors shorter than $1.1,2.1$, and $3.0 \AA$, respectively (Table 2 ). Therefore, the calculated conformational dependence of the studied effective CSAs should not be significantly altered by the $r_{\mathrm{DD}}{ }^{-3}$ scaling. Several selected $(\psi, \varphi)$ surfaces of the scaled effective CSAs (Figures 4 and 5) can be compared to the original $\Delta \sigma^{\text {eff }}$ surfaces (Supporting Information).

The differences of the scaled $\Delta \sigma^{\text {eff }}$ values calculated between the $\beta$-sheet and $\alpha$-helix conformers (Table 2 ) as well as the scaled $\Delta \sigma^{\text {eff }}$ ranges (Table 2, Figure $6 \mathrm{~B}$ ) were evaluated consistently with the original effective CSAs. Significantly large values of the scaled $\Delta \sigma^{\text {eff }}$ were obtained for the experimentally probed $\mathrm{C}^{\prime}-\mathrm{C}_{\alpha 1} \mathrm{H}_{\alpha 1}, \mathrm{C}^{\prime}-\mathrm{NH}_{\mathrm{N}}, \mathrm{N}-\mathrm{C}_{\alpha 1} \mathrm{H}_{\alpha 1}, \mathrm{~N}-\mathrm{C}_{\alpha 2} \mathrm{H}_{\alpha 2}$, and $\mathrm{N}-\mathrm{NH}_{\mathrm{N}}$ cross-correlations (Table 2 and references therein, Figure $6 \mathrm{~B})$. The $\mathrm{C}^{\prime}-\mathrm{C}_{\alpha 2} \mathrm{H}_{\alpha 2}, \mathrm{~N}-\mathrm{NH}_{\alpha 2}$, and $\mathrm{N}-\mathrm{C}^{\prime} \mathrm{H}_{\alpha 1}$ crosscorrelations, for which an experimental reference was not available, and which were theoretically modeled only in this work, appeared after the scaling with similarly good prerequisites for application in conformational studies of peptide backbone as those CCRs already experimentally tested.

In particular, the $\mathrm{C}^{\prime}-\mathrm{C}_{\alpha 2} \mathrm{H}_{\alpha 2}$ cross-correlation had a range of $\Delta \sigma^{\text {eff }}$ values equivalent to its complement $\mathrm{C}^{\prime}-\mathrm{C}_{\alpha 1} \mathrm{H}_{\alpha 1}$ involving the $\mathrm{C}_{\alpha 1} \mathrm{H}_{\alpha 1}$ dipolar vector (Table 2, Figure $6 \mathrm{~B}$ ). While the $\Delta \sigma^{\text {eff }}$ calculated for the $\mathrm{C}^{\prime}-\mathrm{C}_{\alpha 1} \mathrm{H}_{\alpha 1}$ cross-correlation depended dominantly on the $\psi$ torsion, the choice of the $\mathrm{NH}_{\mathrm{N}}$ dipolar vector for the same CSA dramatically changed the shape and other characteristics of the $\Delta \sigma^{\text {eff }}$ surface (Figure 4 , Table 2). Of the other cross-correlations involving the carbonyl carbon, the $\mathrm{C}^{\prime}-\mathrm{NH}_{\mathrm{N}}$ was the only scaled $\Delta \sigma^{\text {eff }}$ that still possessed a relatively large range of values. However, the scaled $\Delta \sigma^{\text {eff }}$ surfaces were significantly modulated in both the $\psi$ and the $\varphi$ dimensions for all forms of the LALA molecule (Figure 4), and the charge of the terminal groups also had a notable impact (Figures 4 and 6B).

The cross-correlations involving the amide nitrogen CSA were shown to be overall more suitable for peptide structural studies than those involving the carbonyl carbon CSA. For a given dipolar interaction, the range of the scaled $\Delta \sigma^{\text {eff }}$ values was almost always larger for the N-DD type of cross-correlation than for the $C^{\prime}-$ DD type (Table 2, Figure 6B). Such behavior could have been expected from a well-known fact that the amide ${ }^{15} \mathrm{~N}$ CSA is larger than the carbonyl ${ }^{13} \mathrm{C} \mathrm{CSA} .{ }^{60}$ Interestingly, the scaled $\Delta \sigma^{\text {eff }}(\psi, \varphi)$ surfaces for the experimentally probed $\mathrm{N}-\mathrm{C}_{\alpha 1} \mathrm{H}_{\alpha 1}$ and $\mathrm{N}-\mathrm{C}_{\alpha 2} \mathrm{H}_{\alpha 2}$ cross-correlations ${ }^{18,19}$ were rather smooth and depended almost exclusively on one backbone torsion only. On the contrary, the scaled $\Delta \sigma^{\text {eff }}$ surfaces for the experimentally most convenient $\mathrm{N}-\mathrm{NH}_{\mathrm{N}}$ cross-correlation ${ }^{10,37,46}$ were significantly modulated in both dimensions, which renders its structural interpretation difficult (Table 2, Figure 5), although not unsuitable in the form of restraints.

The promising $\mathrm{N}-\mathrm{NH}_{\alpha 2}$ and $\mathrm{N}-\mathrm{C}^{\prime} \mathrm{H}_{\alpha 1}$ cross-correlations, which had not been reported previously, involved the amide nitrogen CSA and relatively long DD vectors $\left(r_{\mathrm{DD}} \sim 2.1 \AA\right.$, Table 2). Although the calculated ranges of the scaled $\Delta \sigma^{\text {eff }}$ values were somewhat smaller compared to the experimentally probed cross-correlations discussed above (Table 2, Figure 6B), they exhibited a rather smooth dependence on only one of the two backbone torsions (Table 2, Figure 5) and a negligible $\mathrm{pH}$ variation. Moreover, the $\mathrm{N}-\mathrm{NH}_{\alpha 2}$ cross-correlation mechanism involves only two nuclei, which is experimentally favorable. These two cross-correlations probably represent the best performing examples of the CSA-DD mechanism involving the dipolar interaction between not directly bonded atoms.

The following cross-correlations, which were not yet measured, can be probably also considered useful for the peptide backbone structural studies, namely because they depended dominantly on a single torsion only: $\mathrm{C}^{\prime}-\mathrm{NH}_{\alpha 1}, \mathrm{C}^{\prime}-\mathrm{NH}_{\alpha 2}$, $\mathrm{C}^{\prime}-\mathrm{C}^{\prime} \mathrm{H}_{\alpha 1}, \mathrm{~N}-\mathrm{NH}_{\alpha 1}$, and $\mathrm{N}-\mathrm{C}^{\prime} \mathrm{H}_{\alpha 2}$ (Table 2, Figure 6B). The other cross-correlation mechanisms, among which the $\mathrm{C}^{\prime}-\mathrm{C}^{\prime} \mathrm{H}_{\mathrm{N}}$ and $\mathrm{N}-\mathrm{C}^{\prime} \mathrm{H}_{\mathrm{N}}$ experimentally probed CCRs can be counted, possessed either a small range of the scaled $\Delta \sigma^{\text {eff }}$ values on the $(\psi, \varphi)$ grid, or the surfaces were modulated in both $\psi$ and $\varphi$ dimensions. Their usability in peptide structural studies is therefore limited.

\section{Conclusion}

The calculated dependencies of the effective chemical shielding anisotropies on the main backbone torsion angles $\psi$ and $\varphi$ in the cationic, zwitterionic, and anionic forms of the L-alanylL-alanine peptide were analyzed in order to assess the applicability of the corresponding cross-correlated relaxation rates in structural studies of oligopeptides and proteins. The analysis of the calculated effective CSAs was focused on the overall character of their dependence on backbone conformation and molecular charge, on their usability for distinguishing between the $\beta$-sheet and $\alpha$-helix backbone conformations, and on the effect of scaling by the length of the dipolar vector.

The 20 cross-correlated relaxation mechanisms studied in this work involved either the amide nitrogen CSA or the carbonyl carbon CSA and dipolar vectors connecting $\alpha$-carbon, carbonyl carbon, or amide nitrogen to amide hydrogen or $\alpha$-hydrogen.

The effective CSAs generally depend on both backbone torsion angles, but for the $\mathrm{X}-\mathrm{C}_{\alpha} \mathrm{H}_{\alpha}, \mathrm{X}-\mathrm{NH}_{\alpha}, \mathrm{X}-\mathrm{C}^{\prime} \mathrm{H}_{\alpha 1}$, and $\mathrm{N}-\mathrm{C}^{\prime} \mathrm{H}_{\alpha 2}\left(\mathrm{X}=\mathrm{C}^{\prime}, \mathrm{N} ; \alpha=\alpha 1, \alpha 2\right)$ effective CSAs, a dominant dependence on a single torsion angle was observed. The amide nitrogen effective CSAs showed an overall clearer dependence on only one of the two backbone torsions with a smaller variation by the molecular charge compared to the carbonyl carbon effective CSAs. The cross-correlations involving the amide nitrogen also exhibited larger ranges of the effective CSA values, which probably implies their better usability in peptide structural studies.

By taking into account the length of the dipolar vector, a more conclusive estimate of the cross-correlated relaxation rates and their relative magnitudes was obtained. The cross-correlations involving the dipolar vectors with a length corresponding to a single covalent bond $\left(\mathrm{X}-\mathrm{C}_{\alpha} \mathrm{H}_{\alpha}, \mathrm{X}-\mathrm{NH}_{\mathrm{N}} ; r_{\mathrm{DD}} \sim 1.1 \AA\right.$ ) expectedly provided the largest calculated ranges of the scaled effective CSAs. The complex analysis carried out for the effective CSAs showed that the $\mathrm{X}-\mathrm{C}_{\alpha} \mathrm{H}_{\alpha}$ cross-correlations probed in recent experimental studies ${ }^{18-20,24}$ are best suited for the determination of both $\psi$ and $\varphi$ peptide backbone torsion 
angles. The dipolar scaling damped down most of the other investigated effective CSAs that would otherwise be also attractive due to their large effective CSA ranges and dominant dependence on a single torsion angle (namely the $\mathrm{C}^{\prime}-\mathrm{NH}_{\alpha 1}$, $\mathrm{C}^{\prime}-\mathrm{NH}_{\alpha 2}, \mathrm{C}^{\prime}-\mathrm{C}^{\prime} \mathrm{H}_{\alpha 1}, \mathrm{~N}-\mathrm{NH}_{\alpha 1}$, and $\mathrm{N}-\mathrm{C}^{\prime} \mathrm{H}_{\alpha 2}$ effective CSAs). Finally, the $\mathrm{N}-\mathrm{NH}_{\alpha 2}$ and $\mathrm{N}-\mathrm{C}^{\prime} \mathrm{H}_{\alpha 1}$ cross-correlations involving the dipolar vectors of intermediate length $\left(r_{\mathrm{DD}} \sim 2.1 \AA\right)$ were classified as the most promising candidates for peptide backbone structural studies, which should be probed experimentally in the future. To assess the weaker cross-correlation effects predicted in this paper reliably, highly sensitive experiments and high accuracy of the measurements are a stringent requirement. The symmetrical reconversion schemes introduced by Bodenhausen's group ${ }^{37,61}$ provide valuable approaches for this.

Acknowledgment. This work was supported by the Academy of Sciences of the Czech Republic, Grants IAA400550701, A4005507020, and AV0Z40550506. V.S. was supported by a Human Frontier Science Program (HFSP) Young Investigator's Grant. We also acknowledge support by the ÖAD Kontakt (AT-CZ) program Project No. CZ 08/2007-KONTAKT 2007/5.

Supporting Information Available: The calculated surfaces of all 20 effective CSAs in the three forms of the LALA molecule. This material is available free of charge via the Internet at http://pubs.acs.org.

\section{References and Notes}

(1) Downing, K. A. Protein NMR Techniques, 2nd ed.; Humana Press: Totowa, NJ, 2004; Vol. 278

(2) James, T. L.; Dotsch, V.; Schmitz, U. Nuclear Magnetic Resonance of Biological Macromolecules Part A, 1st ed.; Elsevier: New York, 2001; Vol. 338.

(3) Wijmenga, S. S.; van Buuren, B. N. M. Prog. Nucl. Magn. Reson. Spectrosc. 1998, 32, 287.

(4) Mollova, E. T.; Hansen, M. R.; Pardi, A. J. Am. Chem. Soc. 2000 , 122,11561

(5) Grzesiek, S.; Cordier, F.; Jaravine, V.; Barfield, M. Prog. NMR Spectrosc. 2004, 45, 275.

(6) Flinders, J.; Dieckmann, T. Prog. NMR Spectrosc. 2006, 48, 137.

(7) Tanaka, Y.; Ono, A. Dalton Trans. 2008, 4965.

(8) Lipsitz, R. S.; Tjandra, N. Annu. Rev. Biophys. Biomol. Struct. 2004, $33,387$.

(9) Reif, B.; Hennig, M.; Griesinger, C. Science 1997, 276, 1230.

(10) Kroenke, C. D.; Loria, J. P.; Lee, L. K.; Rance, M.; Palmer, A. G. J. Am. Chem. Soc. 1998, 120, 7905.

(11) Pang, Y. X.; Wang, L. C.; Pellecchia, M.; Kurochkin, A. V.; Zuiderweg, E. R. P. J. Biomol. NMR 1999, 14, 297.

(12) Carlomagno, T.; Maurer, M.; Hennig, M.; Griesinger, C. J. Am. Chem. Soc. 2000, 122, 5105.

(13) Banci, L.; Bertini, I.; Felli, I. C.; Hajieva, P.; Viezzoli, M. S. J. Biomol. NMR 2001, 20, 1.

(14) Chiarparin, E.; Rudisser, S.; Bodenhausen, G. ChemPhysChem 2001, 2, 41

(15) Ravindranathan, S.; Kim, C. H.; Bodenhausen, G. J. Biomol. NMR 2003, 27, 365

(16) Vugmeyster, L.; Perazzolo, C.; Wist, J.; Frueh, D.; Bodenhausen, G. J. Biomol. NMR 2004, 28, 173 .

(17) Wang, T. Z.; Frederick, K. K.; Igumenova, T. I.; Wand, A. J.; Zuiderweg, E. R. P. J. Am. Chem. Soc. 2005, 127, 828.

(18) Hong, M.; Gross, J. D.; Hu, W.; Griffin, R. G. J. Magn. Reson. 1998, $135,169$.

(19) Reif, B.; Diener, A.; Hennig, M.; Maurer, M.; Griesinger, C. J. Magn. Reson. 2000, 143, 45.

(20) Yang, D. W.; Konrat, R.; Kay, L. E. J. Am. Chem. Soc. 1997, 119,

(21) Yang, D. W.; Kay, L. E. J. Am. Chem. Soc. 1998, 120, 9880.

(22) Pelupessy, P.; Chiarparin, E.; Ghose, R.; Bodenhausen, G. J. Biomol. NMR 1999, 13,375.

(23) Pelupessy, P.; Chiarparin, E.; Ghose, R.; Bodenhausen, G. J. Biomol. NMR 1999, 14, 277 .

(24) Chiarparin, E.; Pelupessy, P.; Ghose, R.; Bodenhausen, G. J. Am. Chem. Soc. 1999, 121, 6876.

(25) Chiarparin, E.; Pelupessy, P.; Ghose, R.; Bodenhausen, G. J. Am. Chem. Soc. 2000, 122, 1758.
(26) Carlomagno, T.; Felli, I. C.; Czech, M.; Fischer, R.; Sprinzl, M.; Griesinger, C. J. Am. Chem. Soc. 1999, 121, 1945.

(27) Felli, I. C.; Richter, C.; Griesinger, C.; Schwalbe, H. J. Am. Chem. Soc. 1999, 121, 1956.

(28) Richter, C.; Griesinger, C.; Felli, I.; Cole, P. T.; Varani, G.; Schwalbe, H. J. Biomol. NMR 1999, 15, 241.

(29) Richter, C.; Reif, B.; Griesinger, C.; Schwalbe, H. J. Am. Chem. Soc. 2000, 122, 12728.

(30) Riek, R. J. Magn. Reson. 2001, 149, 149

(31) Carlomagno, T.; Blommers, M. J. J.; Meiler, J.; Cuenoud, B.; Griesinger, C. J. Am. Chem. Soc. 2001, 123, 7364.

(32) Duchardt, E.; Richter, C.; Ohlenschlager, O.; Gorlach, M.; Wohnert, J.; Schwalbe, H. J. Am. Chem. Soc. 2004, 126, 1962.

(33) Rinnenthal, J.; Richter, C.; Ferner, J.; Duchardt, E.; Schwalbe, H. J. Biomol. NMR 2007, 39, 17.

(34) Pang, Y. X.; Zuiderweg, E. R. P. J. Am. Chem. Soc. 2000, 122, 4841.

(35) Cornilescu, G.; Bax, A. J. Am. Chem. Soc. 2000, 122, 10143.

(36) Cisnetti, F.; Loth, K.; Pelupessy, P.; Bodenhausen, G. ChemPhysChem 2004, 5, 807.

(37) Loth, K.; Pelupessy, P.; Bodenhausen, G. J. Am. Chem. Soc. 2005, 127,6062 .

(38) Konrat, R.; Sterk, H. Chem. Phys. Lett. 1993, 203, 75.

(39) Ghalebani, L.; Bernatowicz, P.; Aski, S. N.; Kowalewski, J. Concepts Magn. Reson., Part A 2007, 30A, 100.

(40) Tugarinov, V.; Shapiro, Y. E.; Liang, Z. C.; Freed, J. H.; Meirovitch, E. J. Mol. Biol. 2002, 315, 155 .

(41) Meirovitch, E.; Shapiro, Y. E.; Polimeno, A.; Freed, J. H. J. Phys. Chem. A 2006, 110, 8366

(42) Kaupp, M.; Bühl, M.; Malkin, V. Calculation of NMR and EPR parameters; Wiley-VCH Verlag: Weinheim, 2004.

(43) Bartoschek, S.; Buurman, G.; Geierstanger, B. H.; Lapham, J.; Griesinger, C. J. Am. Chem. Soc. 2003, 125, 13308.

(44) Markwick, P. R. L.; Sattler, M. J. Am. Chem. Soc. 2004, 126, 11424.

(45) Sychrovský, V.; Müller, N.; Schneider, B.; Smrečki, V.; Špirko, V.; Šponer, J.; Trantírek, L. J. Am. Chem. Soc. 2005, 127, 14663.

(46) Brutscher, B.; Skrynnikov, N. R.; Bremi, T.; Bruschweiler, R.; Ernst,

R. R. J. Magn. Reson. 1998, 130, 346.

(47) Bouř, P.; Buděšínský, M.; Špirko, V.; Kapitán, J.; Šebestík, J.; Sychrovský, V. J. Am. Chem. Soc. 2005, 127, 17079.

(48) Sychrovský, V.; Buděšínský, M.; Benda, L.; Špirko, V.; Vokáčová, Z.; Šebestík, J.; Bouř, P. J. Phys. Chem. B 2008, 112, 1796.

(49) Graf, J.; Nguyen, P. H.; Stock, G.; Schwalbe, H. J. Am. Chem. Soc. 2007, 129, 1179 .

(50) Šebek, J.; Gyurcsik, B.; Šebestík, J.; Kejík, Z.; Bednárová, L.; Bouř, P. J. Phys. Chem. A 2007, 111, 2750.

(51) Kowalewski, J.; Mäler, L. Nuclear Spin Relaxation in Liquids: Theory, Experiments, and Applications, Taylor \& Francis Group: New York, London, 2006.

(52) Kumar, A.; Grace, R. C. R.; Madhu, P. K. Prog. Nucl. Magn. Reson. Spectrosc. 2000, 37, 191 .

(53) Becke, A. D. Phys. Rev. A 1988, 38, 3098.

(54) Perdew, J. P.; Wang, Y. Phys. Rev. B 1992, 45, 13244.

(55) Krishnan, R.; Binkley, J. S.; Seeger, R.; Pople, J. A. J. Chem. Phys. 1980, 72,650 .

(56) Becke, A. D. J. Chem. Phys. 1993, 98, 5648.

(57) Lee, C. T.; Yang, W. T.; Parr, R. G. Phys. Rev. B 1988, 37, 785.

(58) Kutzelnigg, W.; Fleischer, U.; Schindler, M. NMR, Basic Principles and Progress; Springer: Heidelberg, 1990; Vol. 23.

(59) Frisch, M. J.; Trucks, G. W.; Schlegel, H. B.; Scuseria, G. E.; Robb, M. A.; Cheeseman, J. R.; Montgomery, J. A., Jr.; Vreven, T.; Kudin, K. N.; Burant, J. C.; Millam, J. M.; Iyengar, S. S.; Tomasi, J.; Barone, V.; Mennucci, B.; Cossi, M.; Scalmani, G.; Rega, N.; Petersson, G. A.; Nakatsuji, H.; Hada, M.; Ehara, M.; Toyota, K.; Fukuda, R.; Hasegawa, J.; Ishida, M.; Nakajima, T.; Honda, Y.; Kitao, O.; Nakai, H.; Klene, M.; Li, X.; Knox, J. E.; Hratchian, H. P.; Cross, J. B.; Bakken, V.; Adamo, C.; Jaramillo, J.; Gomperts, R.; Stratmann, R. E.; Yazyev, O.; Austin, A. J.; Cammi, R.; Pomelli, C.; Ochterski, J. W.; Ayala, P. Y.; Morokuma, K.; Voth, G. A.; Salvador, P.; Dannenberg, J. J.; Zakrzewski, V. G.; Dapprich, S.; Daniels, A. D.; Strain, M. C.; Farkas, O.; Malick, D. K.; Rabuck, A. D.; Raghavachari, K.; Foresman, J. B.; Ortiz, J. V.; Cui, Q.; Baboul, A. G.; Clifford, S.; Cioslowski, J.; Stefanov, B. B.; Liu, G.; Liashenko, A.; Piskorz, P.; Komaromi, I.; Martin, R. L.; Fox, D. J.; Keith, T.; Al-Laham, M. A.; Peng, C. Y.; Nanayakkara, A.; Challacombe, M.; Gill, P. M. W.; Johnson, B.; Chen, W.; Wong, M. W.; Gonzalez, C.; Pople, J. A. Gaussian 03, revision C.02; Gaussian, Inc.: Wallingford, CT, 2004.

(60) Hartzell, C. J.; Whitfield, M.; Oas, T. G.; Drobny, G. P. J. Am. Chem. Soc. 1987, 109, 5966.

(61) Pelupessy, P.; Espallargas, G. M.; Bodenhausen, G. J. Magn. Reson. 2003, 161, 258

JP8105452 